\title{
A New Species of Polyodontes (Annelida: Acoetidae) from Western Japan
}

\author{
Naoto Jimi ${ }^{1,5}$, Shinri Tomioka ${ }^{2}$, Ryo Orita ${ }^{3}$, and Hiroshi Kajihara ${ }^{4}$ \\ ${ }^{1}$ Bioscience Group, National Institute of Polar Research, Tachikawa, Tokyo 190-8518, Japan \\ E-mail:beniimo7010@gmail.com \\ ${ }^{2}$ Rishiri Town Museum, Senhoshi, Rishiri Island, Hokkaido 097-0311, Japan \\ ${ }^{3}$ Faculty of Agriculture, Saga University, 1 Honjo-machi, Saga 840-8502, Japan \\ ${ }^{4}$ Faculty of Science, Hokkaido University, Kita 10 Nishi 8 Kitaku, Sapporo, Hokkaido 060-0810, Japan \\ ${ }^{5}$ Corresponding author
}

(Received 4 March 2019; Accepted 24 September 2019)

http://zoobank.org/4CE1B7C2-0C5A-43D9-A626-2005342AF324

\begin{abstract}
Acoetid polychaetes were collected from shallow waters off Kochi Prefecture and Wakayama Prefecture, Japan. The specimens could be assigned to the genus Polyodontes Blainville, 1828, but are different from all the known species of the genus by the following characters: ommatophores with short neck; palps with minute papillae; parapodia without branchiae; the acicular neurochaetae always lacking aristae and having hairs only on a small area of their subdistal end; and antennae with brown dots. They are herein morphologically described as a new species and a partial 658-bp COI sequence as a DNA barcode is provided for future taxonomic studies.
\end{abstract}

Key Words: Kuroshio coastal region, marine invertebrates, North West Pacific, taxonomy.

\section{Introduction}

Acoetids are long-bodied scaleworms, constituting one of the seven families in the suborder Aphroditiformia Levinsen, 1883 (Norlinder et al. 2012). They are ambush predators, waiting for prey in a tube constructed by fibers from spinning glands located in their parapodia (Hutchings 2000). Acoetid polychaetes are widely distributed in the world, but never common in benthos samples (Palmero et al. 2008).

Polyodontes Blainville, 1828 is one of the eight acoetid genera recognized by Pettibone (1989). Members of the genus are widely distributed in warm temperate to tropical waters in depth ranging from the low intertidal to moderate depths (Pettibone 1989; Barnich and Steene 2003). The genus can be discriminated from other acoetids by the following features: ommatophores are present; lateral prostomial antennae are attached ventrally on the ommatophores; and upper type 'a' neurochaetae are spinous but not plumose either distally or subdistally. In Japan, two species of Polyodontes have been recorded: P. atromarginatus Horst, 1917 from northern Japan (Takahashi 1942) and P. maxillosus (Ranzani, 1817) from Okinawa Prefecture (Nishi et al. 2008). Imajima (2001) mentioned specimens of another Polyodontes species from Nagoya (Aichi Prefecture), but their morphology and taxonomic identity have never been published.

In this study, a new acoetid species, collected in Kochi and Wakayama prefectures, Northwest Pacific, is described and a partial cytochrome $c$ oxidase subunit I (COI) sequence is provided as a DNA barcode.

\section{Materials and Methods}

A living specimen was hand-collected by turning a rock during SCUBA diving, $12 \mathrm{~m}$ deep, off the coast of Otsuki, Japan $\left(32^{\circ} 46.41^{\prime} \mathrm{N}, 132^{\circ} 43.98^{\prime} \mathrm{E}\right)$ in 2017 . The specimen was photographed with an Olympus Tough TG-5 digital camera, then fixed in $70 \%$ ethanol. The fixed specimen was observed under a Nikon SMZ1500 dissecting microscope and an Olympus BX51 compound light microscope, and then photographed with a Nikon D5200 digital camera. The specimen has been deposited in the collection of the National Museum of Nature and Science, Tsukuba (NSMT). In addition to the newly collected individual, one specimen, which was collected from Hatakejima, Japan in 1966 and then fixed by $10 \%$ seawater formalin, stored in NSMT was also investigated.

DNA extraction and sequencing of part of the COI were carried out following the methodology described by Jimi and Fujiwara (2016). The newly obtained sequence has been deposited in the DNA Data Bank of Japan (DDBJ).

\section{Taxonomy}

Polyodontes kuroshio sp. nov.

[New Japanese name: kurobuchi-bouseki-urokomushi] (Figs 1, 2)

Material examined. Holotype, NSMT-Pol H-764, sex unknown, $85 \mathrm{~mm}$ long, $7 \mathrm{~mm}$ wide (in segment 8 ) for 92 

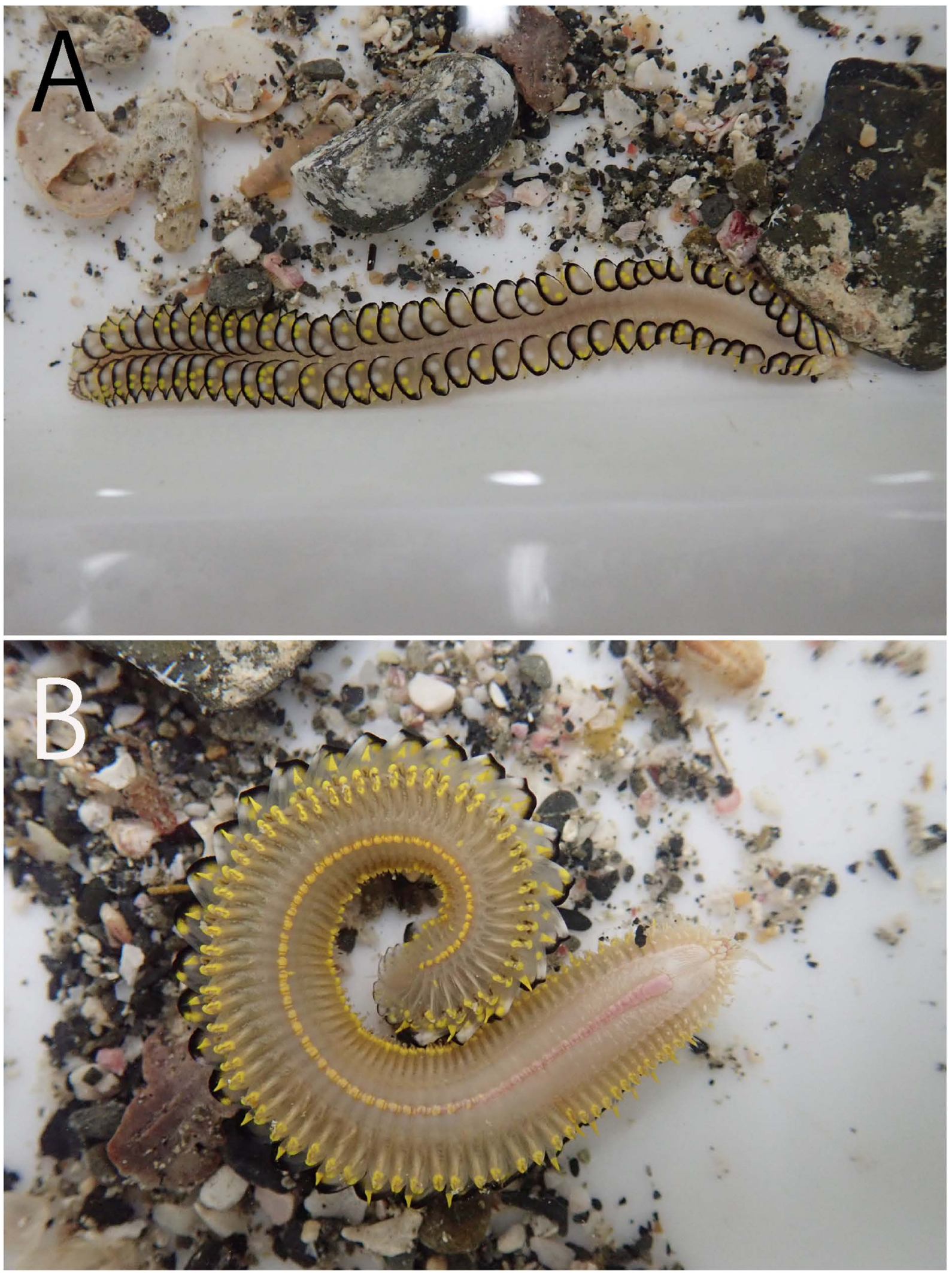

Fig. 1. Polyodontes kuroshio sp. nov., NMST-Pol H-764 (holotype), live specimen. A, dorsal view; B, ventral view.

segments (complete specimen), off Otsuki $\left(32^{\circ} 46.41^{\prime} \mathrm{N}\right.$, $\left.132^{\circ} 43.98^{\prime} \mathrm{E}\right)$, Kochi, Shikoku Island, Japan, Northwest Pacific, 11 October 2017, $12 \mathrm{~m}$ deep, rocky substrate, Naoto Jimi collector. Paratype, NSMT-Pol P-765, sex unknown,
$190 \mathrm{~mm}$ long, $8 \mathrm{~mm}$ wide (in segment 8) for 134 segments (not complete specimen), Hatakejima $\left(33^{\circ} 41.60^{\prime} \mathrm{N}\right.$, $135^{\circ} 22.00^{\prime} \mathrm{E}$ ), Wakayama, Japan, Northwest Pacific, $2 \mathrm{Au}-$ gust 1966, intertidal zone, sandy beach, Fujio Uchinomi col- 


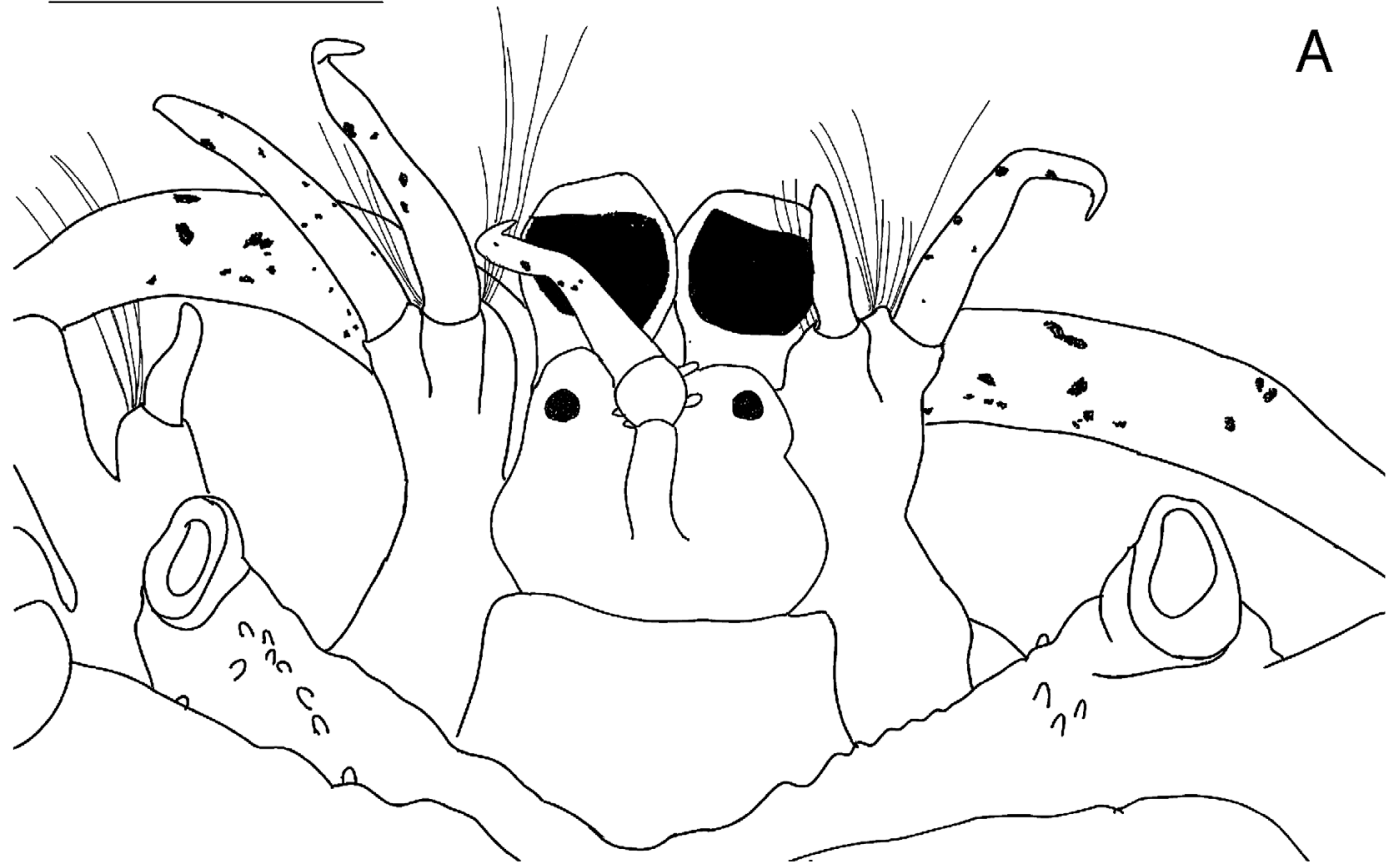

B

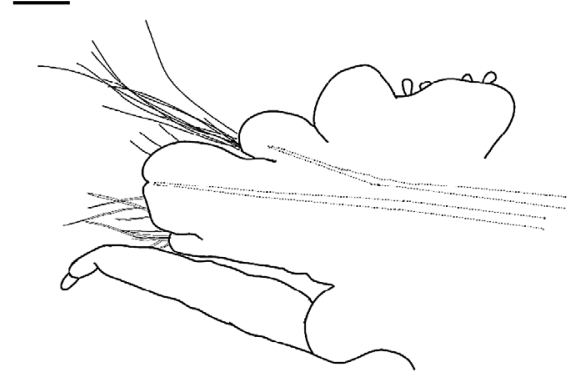

D

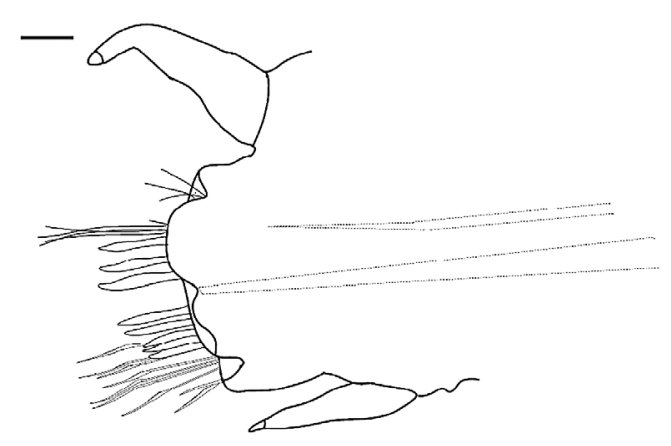

C -

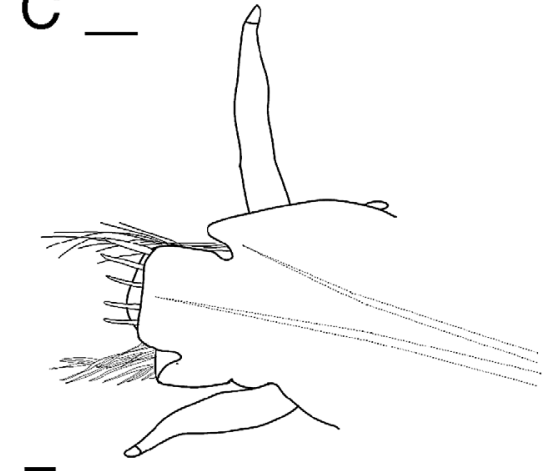

E

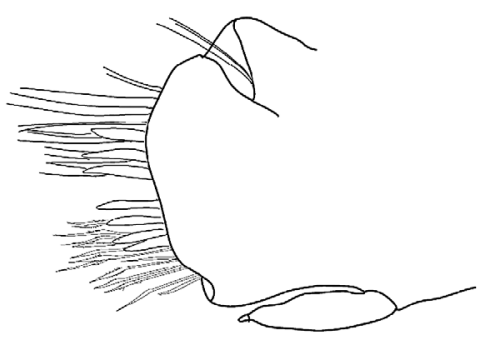

F

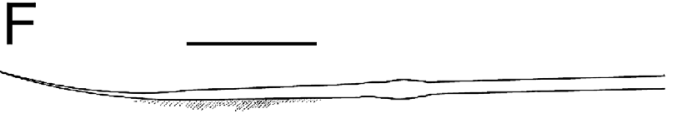

$\mathrm{H}$

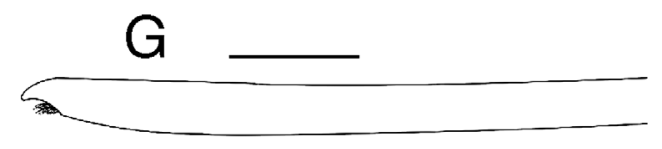

I

Fig. 2. Polyodontes kuroshio sp. nov., NSMT-Pol H-764 (holotype). A, prostomium, dorsal view; B, left parapodium, segment 2, posterior view; C, left parapodium, segment 3, posterior view; D, left parapodium, segment 8, posterior view; E, left parapodium, segment 9, posterior view; F, upper type 'a' neurochaeta (finely spinous), segment 9; G, middle acicular chaeta, segment 60; H, lower curved neurochaeta (with long spines), segment 9; I, upper type 'b' neurochaeta (bipinnate, with widely spaced spines), segment 9. Scale bars: A, $1 \mathrm{~mm}$; B-E, $200 \mu \mathrm{m}$; F-I, $100 \mu \mathrm{m}$. 
lector.

Description based on holotype. Body dorsoventrally flattend. Colour in life: main body dorsally cream white, midventrally with longitudinal yellow line from midbody to posterior end; parapodia and dorsal cirri distally with yellow pigment (Fig. 1A, B). Elytrophores 48 pairs in number, present on segments $2,4,5,7,9,11,13,15,17,19,21,23$, $24,25,26,28$, thereafter on alternate segments to 92 . Elytra smooth, oval; transparent with white and yellow oval spots (in life), bordered by a circle of black pigment (incomplete in anterior two to three elytrae) (Fig. 1A); lateral pouch on elytra present from segment 23 backwards (Fig. 1A). Prostomium bilobed, with globular ommatophores with distal lenses and short necks. Median antenna with short oval ceratophore, inserted at middle of prostomium; ceratophore with lateral papillae; style smooth, as long as ommatophores, white with brown dots (Fig. 2A). Pair of sessile eyes present lateral to ceratophore. Lateral antennae inserted on ventrally below ommatophores and tips extending slightly beyond; styles smooth, white with brown dots. Palps long, with minute papillae, cream white with some brown dots (Fig. 2A). Tentaculophores lateral to prostomium, each with papillae on inner dorsolateral side and a few capillary chaetae. Styles of dorsal and ventral tentacular cirri smooth, of equal lengths, white with brown dots (Fig. 2A).

Segment 2 (Fig. 2B): with biramous parapodia, first pair of elytrophores and many sensory papillae present on dorsal side. Notopodium with rounded acicular lobe and bundle of long, finely spinous capillary notochaetae. Neuropodium wide, subconical, with bifid prechaetal acicular lobe, postchaetal lobe, and free anteroventral bract. Neurochaetae enlarged basally, tapering to capillary tip, with numerous rows of spines; spines shorter in upper type 'a' neurochaetae [as defined by Pettibone (1989)] and longer in lower neurochaetae.

Segment 3 (Fig. 2C) with first pair of tapering, smooth dorsal cirri and some sensory papillae on dorsal side. Notopodium as in segment 2, notochaetae shorter. Neuropodium truncate with small anterodorsal and prominent anteroventral bract. Neurochaetae in three groups [as defined by Pettibone (1989)]: anterodorsal bract with upper type 'a' neruochaetae, finley spinous, tapering to capillary tip; middle acicular neruochaetae with hooked tip, without aristae or subdistal hairs; anteroventral bract with lower curved neurochaetae, with longer spines and tapering to capillary tip.

Segments 4 to 8 (Fig. 2D) with small notopodia and few, short, capillary notochaetae; neuropodia similar to those in segment 3; dorsal sensory papillae absent.

Beginning with segment 9 backwards (Fig. 2E), all parapodia similar in shapre, without dorsal sensory papillae. Notopodium wide, flattened, with notoaciculum, few short capillary notochaetae and spinning glands (white dotted). Neuropodium truncate, with slightly bilobed acicular lobe and smaller anterodorsal and prominent anteroventral bract. Neurochaetae in three groups: $i$ ) upper ones in anterodorsal bract of two types: type 'a' neurochaetae, finley spinous, tapering to capillary tip (Fig. 2F) and type 'b' neurochaetae, much shorter, bipinnate, with widely spaced spines (Fig. 2I); ii) middle acicular neurochaetae with hooked tip and subdistal hairs (Fig. 2G); iii) lower ones in anteroventral bract, curved, with longer spines and tapering to capillary tip (Fig. 2H).

Cirrigerous segments with long, smooth, tapering dorsal cirri, about 1.4 times length of ventral cirri (Fig. 2C, D). Ventral cirri short, tapering, smooth, attached on middle part of parapodia (Fig. 2B-D). On segment 2, ventral cirri elongate (reaching to tip of notochaetae) and projecting from base of neuropodia (Fig. 2B). Parapodia without branchiae. Pygidium cylindrical in shape, achaetous with two conical anal cirri, similar to dorsal cirri. Pharynx with 15 pairs of papillae and 2 pairs of jaws; papillae conical, middorsal one much longer than others.

Etymology. This species is named after the Biological Institute on Kuroshio. The holotype from Sukumo was collected by the first author who received funding by the institution. The specific name is a non-declensive noun.

Distribution. This species is known from off Otsuki (Kochi Prefecture) and Hatakejima island (Wakayama Prefecture), Japan, Northwest Pacific.

Sequence. Partial COI gene, 658 bp (DDBJ No. LC492096), determined from the holotype.

Remarks. The morphological features of Polyodontes kuroshio sp. nov. resemble those of Polyodontes oculeus (Treadwell, 1901), originally described from the Caribbean Sea, in having ommatophores with short neck, palps with minute papillae, and parapodia without branchiae (Pettibone 1989). The new species can be distinguished from P. oculeus by the following features: $i$ ) the acicular neurochaetae always lack aristae and possess hair only on a small area of their subdistal end, while in P. oculeus acicular chaetae may have aristae and possess hairs distributed broadly on their subdistal part; and ii) the median and lateral antennae are sporadically covered with brown dots in life and after preservation, while those of $P$. oculeus do not possess any dots. Polyodontes tidemani Pflugfelder, 1932 is the only species that lacks aristae in the genus. However, the new species can be discriminated by the following features: $i$ ) palps have minute papillae, while those of $P$. tidemani have long papillae; $i$ ) absence of branchiae in all parapodia, while $P$. tidemani with inflated branchiae from segment 13 backwards.

In Japan, $P$. atromarginatus and $P$. maxillosus were reported in previous studies (Takahashi 1941; Nishi et al. 2008). The new species is distinct from $P$. atromarginatus and $P$. maxillosus by its ommatophores with the short neck and by the absence of aristae on the acicular neurochaetae.

\section{Acknowledgments}

We are grateful to Dr. Genki Kobayashi, Mr. Shu Nakachi, and members of Biological Institute on Kuroshio for their help in sampling in Kochi. Dr. Hironori Komatsu helped searching the specimen of NSMT. We also thank two anonymous reviewers for providing informative comments. This study is partly supported by Biological Institute on Kuro- 
shio, JSPS KAKENHI No. JP17J05066 and Research Institute of Marine Invertebrates, Japan (No. 2016IKU-1) to N. Jimi.

\section{References}

Barnich, R. and Steene, R. 2003. Description of a new species of Polyodontes renieri in Blainville, 1828 (Polychaeta: Acoetidae) from Papua New Guinea. The Beagle, Records of the Northern Territory Museum of Arts and Sciences 19: 91-96.

Hutchings, P. A. 2000. Family Acoetidae. Pp. 112-115. In: Beesley, P. L., Ross, G. J. B., and Glasby, C. J. (Eds) Polychaetes and Allied: The southern Synthesis. Fauna of Australia. Vol. 4A Polychaeta, Myzostomida, Pogonophora, Echiura, Sipuncula. CSIRO Publishing, Melbourne.

Imajima, M. 2001. Kankeidoubutsu Tamourui II [Annelida, Polychaeta, Vol. II]. Seibutsu Kenkyusha, Tokyo, 542 pp. [In Japanese]

Jimi, N. and Fujiwara, Y. 2016. New species of Trophoniella from Shimoda, Japan (Annelida, Flabelligeridae). ZooKeys 614: 1-13.
Nishi, E., Tanaka, K., and Mori, K. 2008. Records of Acoetes jogasimae (Izuka) from Ariake Sound and Polydontes atromarginatus Horst from Awase tidal flat, Okinawa (Annelida, Polychaeta, Acoetidae). Nankiseibutu 50: 116-118. [In Japanese]

Norlinder, E., Nygren, A., Wiklund, H., and Pleijel, F. 2012. Phylogeny of scale-worms (Aphroditiformia, Annelida), assessed from 18SrRNA, 28SrRNA, 16SrRNA, mithochondrial cytochrome c oxidase subunit I (COI), and morphology. Molecular Phylogenetics and Evolution 65: 490-500.

Palmero, A. M., Martínez, A., Brito, M. C., and Núñez, J. 2008. Acoetidae (Annelida, Polychaeta) from the Iberian Peninsula, Madeira and Canary Islands, with description of a new species. Life and Marine Sciences 25: 49-62.

Pettibone, M. H. 1989. Revision of the aphroditoid polychaetes of the family Acoetidae Kinberg (=Polyodontidae Augener) and reestablishment of Acoetes Audouin and Milne-Edwards, 1832, and Euarche Ehlers, 1887. Smithsonian Contributions to Zoology 464: $1-148$.

Takahashi, K. 1941. Collection notes of polychaetes from northern Japan. Shokubutsu oyobi Doubutsu (Botany and Animals) 9: 587591. [In Japanese] 